\title{
Anomalies of the Fetal Face
}

\author{
${ }^{1}$ E Merz, ${ }^{2} \mathrm{~S}$ Pashaj
}

\begin{abstract}
Visualization of the fetal face with three- and four-dimensional (3D/4D) ultrasound is a unique experience for both, the parents-to-be and the operator. While the future parents are primarily interested in seeing the surface of the fetal face and facial movements, the operator uses the different display modes for a precise fetal malformation check. The multiplanar mode with a simultaneous display of the three perpendicular planes allows an accurate demonstration of a normal or an abnormal fetal profile. Even if an image of the fetal face is acquired in an oblique position, the stored volume can be rotated by the rotational controls in all three directions, until the face is seen precisely in the median plane. The different surface modes enable the operator to detect abnormal protuberant structures or surface defects, while the transparent mode (maximum mode) reveals ossification defects. During a targeted ultrasound examination of the fetal face, five different regions have to be assessed: the forehead, orbits and eyes, nose, mouth, and chin. With 3D ultrasound the following fetal anomalies can be detected: anomalies including the forehead (anencephaly, protuberant forehead, abnormal metopic suture, frontal encephalocele/meningocele), anomalies of the orbits and the eyes (orbital hypoplasia/microphthalmia, hypertelorism, hypotelorism,cataract, nasolacrimal cyst/dacryocystocele,cyclopia/proboscis), abnormalities of the nose (flat nose, absent nasal bone), abnormalities of the mouth (cleft lip/cleft palate, epignathus, macroglossia, chin anomaly (retrognathia/micrognathia). 3D ultrasonography allows a comprehensive evaluation of the fetal face with different display modes. In contrast to 2D ultrasound, 3D ultrasound enables a detailed demonstration of the soft tissue of the fetal face and thus contributes to a better understanding of the malformation by both the physician and the future parents.
\end{abstract}

Keywords: Congenital anomalies, Fetal face, Three-/Fourdimensional ultrasonography.

How to cite this article: Merz E, Pashaj S. Anomalies of the Fetal Face. Donald School J Ultrasound Obstet Gynecol 2019;13(1):34-40.

Source of support: Nil

Conflict of interest: None

\section{INTRODUCTION}

Visualization of the fetal face with 3D/4D ultrasound is a unique experience for both, the parents-to-be and the

${ }^{1}$ Professor and Head, ${ }^{2}$ Consultant

${ }^{1,2}$ Center for Ultrasound and Prenatal Medicine, Frankfurt/Main, Germany

Corresponding Author: E Merz, Professor and Head, Center for Ultrasound and Prenatal Medicine, Frankfurt/Main, Germany, e-mail: merz.eberhard@web.de operator. While the future parents are primarily interested in seeing the surface of the fetal face and facial movements, the operator uses the different display modes for a precise fetal malformation check. ${ }^{1}$ The multiplanar mode with a simultaneous display of the three perpendicular planes allows an accurate demonstration of a normal or an abnormal fetal profile. Even if an image of the fetal face is acquired in an oblique position, the stored volume can be rotated by the rotational controls in all three directions, until the face is seen precisely in the median plane. The different surface modes enable the operator to detect abnormal protuberant structures or surface defects, while the transparent mode (maximum mode) reveals ossification defects.

During a targeted ultrasound examination of the fetal face, five different regions have to be assessed: the forehead, orbits and eyes, nose, mouth, and chin.

\section{ANOMALIES INCLUDING THE FOREHEAD}

\section{Anencephaly}

Anencephaly is the most common and severe anomaly of the central nervous system with an incidence rate of 1:1000 births. The surface demonstration of the fetal head shows an absent superior vault, the missing cerebrum and large bulging eyes ("frog eyes") (Fig. 1). The respective ultrasound appearance of the face has also been described as "Mickey Mouse face". ${ }^{2}$ Anencephaly can be detected as early as 9-10 week's gestation. ${ }^{3,4}$

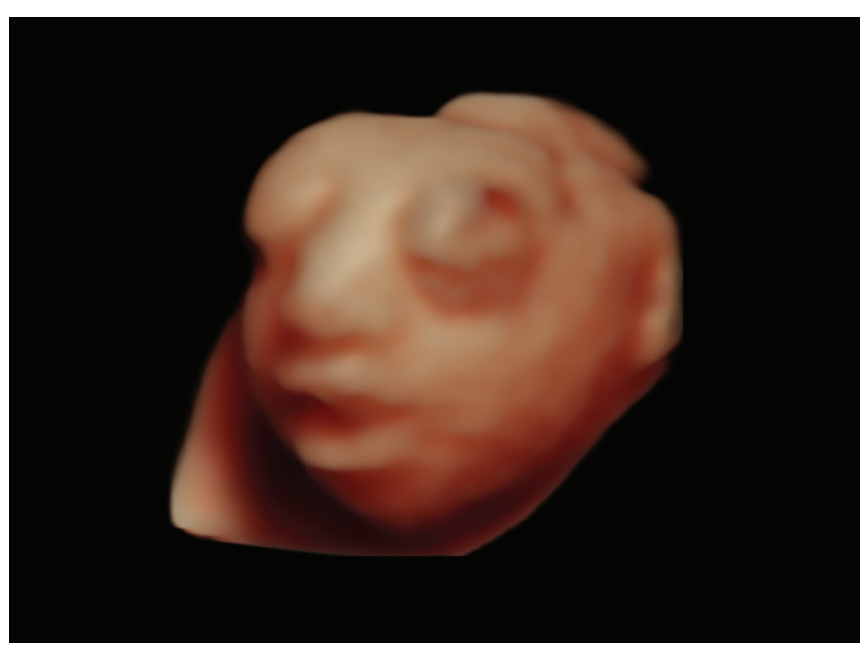

Fig. 1: Surface view (HDlive) of an anencephalus at 30 weeks' gestation 


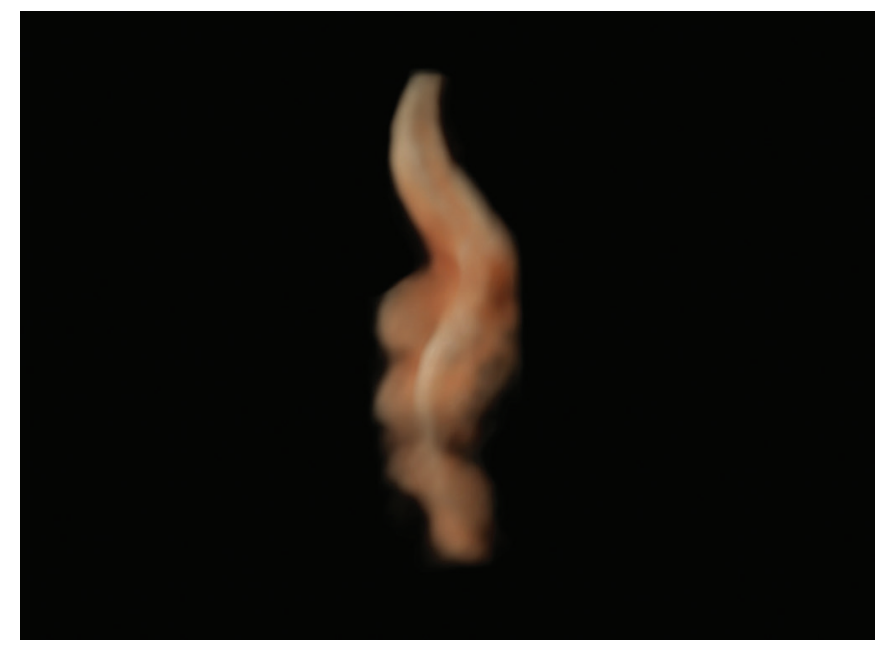

Fig. 2: Achondroplasia (37 weeks' gestation). The profile (lateral surface view) of the fetal face shows pronounced frontal bossing

\section{Protuberant Forehead}

The term frontal bossing refers to the development of an unusually pronounced forehead caused by an enlargement of the frontal bone. In several cases, it has been observed in conjunction with abnormal enlargement of other facial bones. A protuberant forehead may be observed in different fetal abnormalities, such as achondroplasia, Crouzon syndrome, Fragile $\mathrm{X}$ syndrome, Hurler syndrome, Marfan syndrome, Pfeiffer syndrome, Rubinstein-Taybi syndrome, and Russell-Silver syndrome. Moderate frontal bossing may also be seen in some normal fetuses.

Sonographically, frontal bossing is best seen in a side view (Fig. 2), but it can also be unambiguously demonstrated in a frontal surface view.

\section{ABNORMAL METOPIC SUTURE}

The metopic suture can be demonstrated in the transparent mode from a front view (Fig. 3).

\section{Wide Metopic Suture}

Wide V-, Y- and U-shaped metopic sutures have been observed in fetuses with facial defects involving the orbits, nasal bones, lip, the palate, and mandible, as well as in fetuses with cerebellar abnormalities (Chaoui). ${ }^{5} \mathrm{~A}$ wide V-shaped metopic suture can also be observed in fetuses with chromosomal defects (Fig. 3A) or in those with osteogenesis imperfecta type II.

\section{Narrow Metopic Suture}

Premature closure of the suture (craniosynostosis) or the presence of an additional bone between the frontal bones may be a sign for holoprosencephaly and abnormalities of the corpus callosum. ${ }^{5}$ Premature closure of the

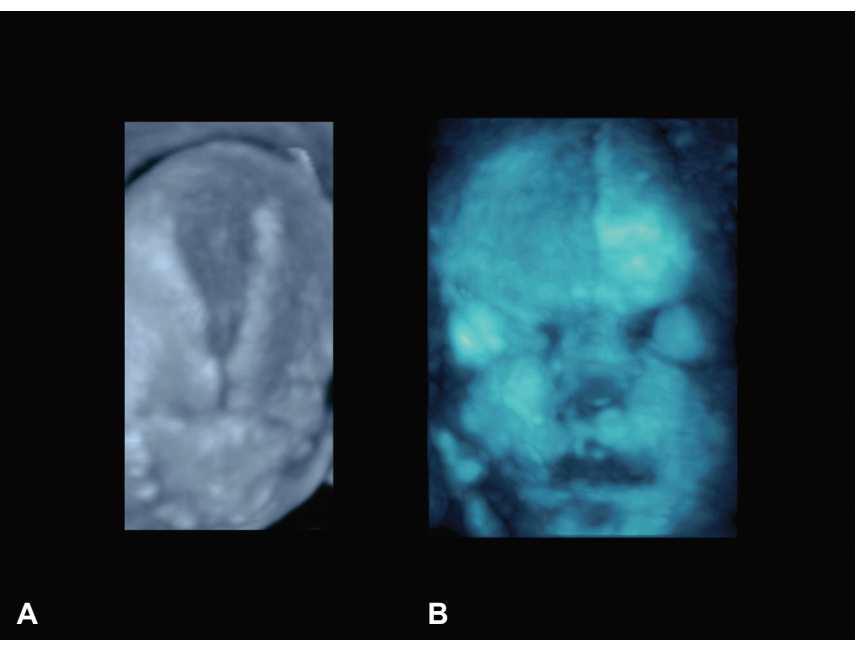

Figs $3 A$ and B: Transparent demonstration of the skull from a front view.(A) Wide $\mathrm{V}$-shaped metopic suture in a fetus with trisomy 22 (20 weeks' gestation); (B) Premature closure of the metopic suture in Apert syndrome (37 weeks' gestation)

metopic suture is also found in Apert syndrome (Fig. 3B). Fetal neurosonography is mandatory in all fetuses with craniosynostosis.

\section{Frontal Encephalocele/Meningocele}

Frontoethmoidal encephalocele represents a frontal skull defect with herniated brain substance. This is in contrast to frontal meningocele where the herniation contains only leptomeninges with cerebrospinal fluid. The incidence of frontoethmoidal encephalocele is 1:40,000 live births. ${ }^{6}$ The presence of a frontal lesion has been observed in $15 \%$ of all encephaloceles. ${ }^{7}$

A frontoethmoidal encephalocele is identified sonographically as a cystic solid mass between the orbits. In the presence of a frontal meningocele, only a hernial sac filled with liquid is observed between the orbits (Fig. 4A). In both findings, a skull defect is visualized behind the protrusion (Fig. 4B).

\section{ANOMALIES OF THE ORBITS AND THE EYES}

\section{Orbital Hypoplasia/Microphthalmia}

In orbital hypoplasia, the orbital size ranges below the 5 th percentile and the eye may be abnormally small (Fig. 5). ${ }^{8}$ The most extreme situation is encountered in anophthalmia where the eye is completely missing from the orbit. Microphthalmia may occur as an isolated abnormality, but is also seen in chromosomal defects (trisomy 13, triploidy), holoprosencephaly and various other syndromes. ${ }^{9}$

\section{Hypertelorism}

Hypertelorism is defined as an abnormally increased interorbital distance (inner and outer orbital distances) above the 95th percentile. ${ }^{8}$ A number of different fetal 


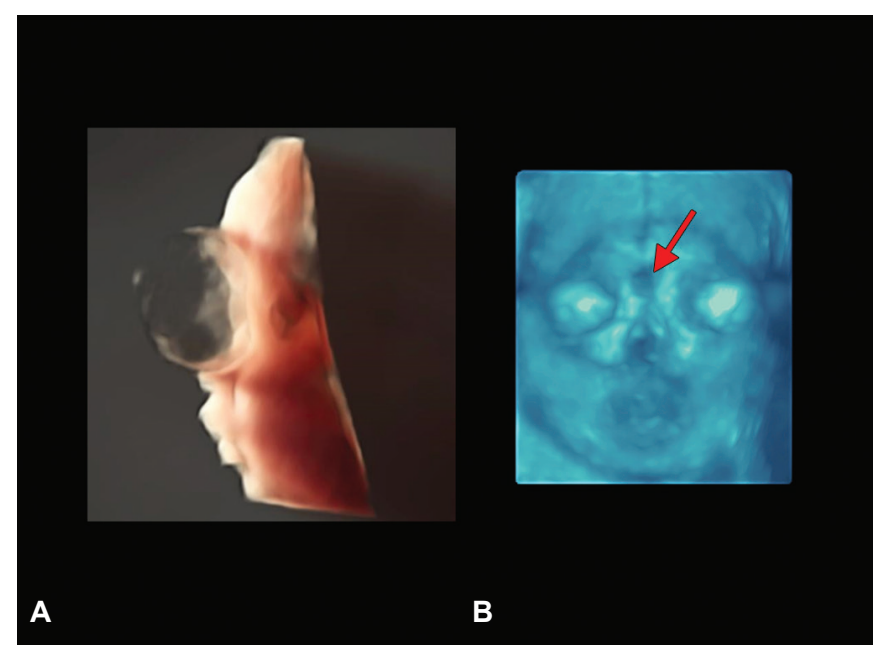

Figs 4A and B: Frontal meningocele at 34 weeks' gestation. (A) Surface side view (HDlive Studio), showing cystic mass in front of the orbits. Only liquid but no brain tissue is seen inside the herniated sac; (B) Transparent view of the fetal face, demonstrating the bony defect between the orbits $(\leftarrow)$

anomalies associated with hypertelorism has been described: chromosome anomalies, various syndromes (e.g., Apert syndrome, Crouzon syndrome), ethmoidal encephalocele and facial haemangioma. ${ }^{9}$

Ultrasonic measurements of the inner and the outer orbital distances can be performed in both the coronal (Fig. 6A) and axial demonstration of the orbits.

The high risk for associated malformations requires both, a targeted ultrasound examination and karyotyping.

\section{Hypotelorism}

Hypotelorism is defined as a decreased interorbital distance below the 5 th percentile. ${ }^{8}$ There is a high risk for associated malformations (chromosome anomalies,

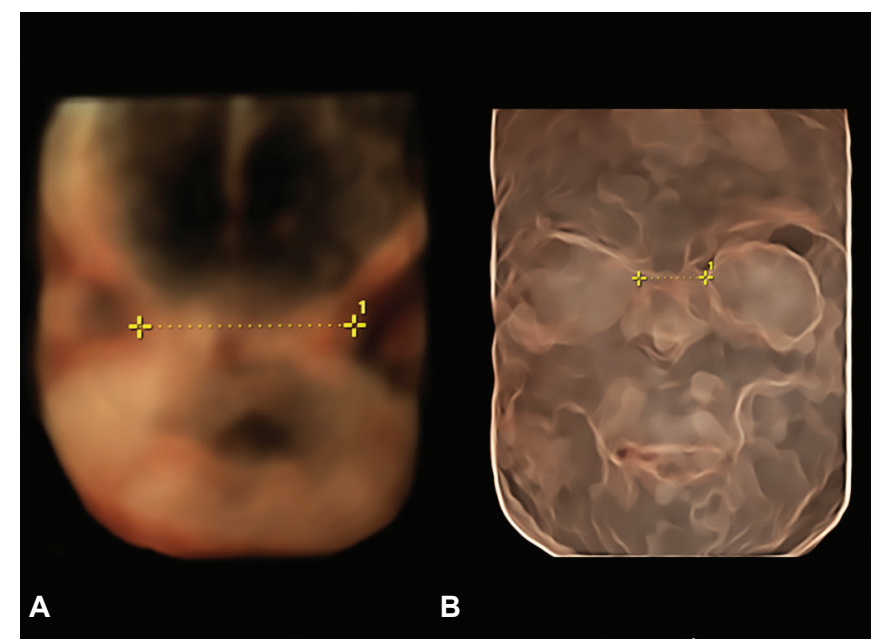

Figs 6A and B: (A) Enlarged interorbital distance (34 mm) revealing hypertelorism (transparent mode, 32 weeks' gestation); (B) Reduced interorbital distance $(8 \mathrm{~mm})$ showing hypotelorism (silhouette mode,28 weeks' gestation)

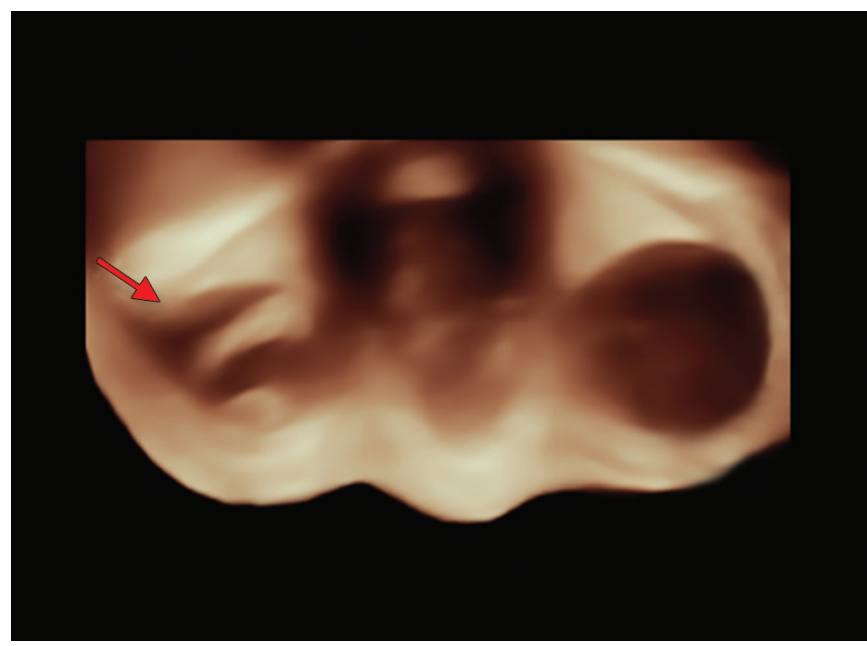

Fig. 5: Orbital hypoplasia right $(\rightarrow)$. Axial surface view, showing small orbita size (right) in comparison to normal orbita (left). 33 weeks' gestation

holoprosencephaly, microcephaly, and Meckel syndrome. ${ }^{9}$ As in hypertelorism, measurements of the inner and the outer orbital distances can be performed in the coronal (Fig. 6B) or axial demonstration of the orbits.

\section{Cataract}

A cataract is an opacification of the crystalline lens in the eye. Cataracts represent a rare fetal condition that may be caused by intrauterine infections (cytomegaly, rubella, varicella), and chromosome abnormalities (trisomies 13, $18,21)$, or it may form a part of a syndrome. ${ }^{10-15}$

A beginning cataract appears sonographically as a hyperechoic dot in the fetal lens, and a complete cataract is visualized as a solid hyperechoic disc in the lens (Fig. 7).

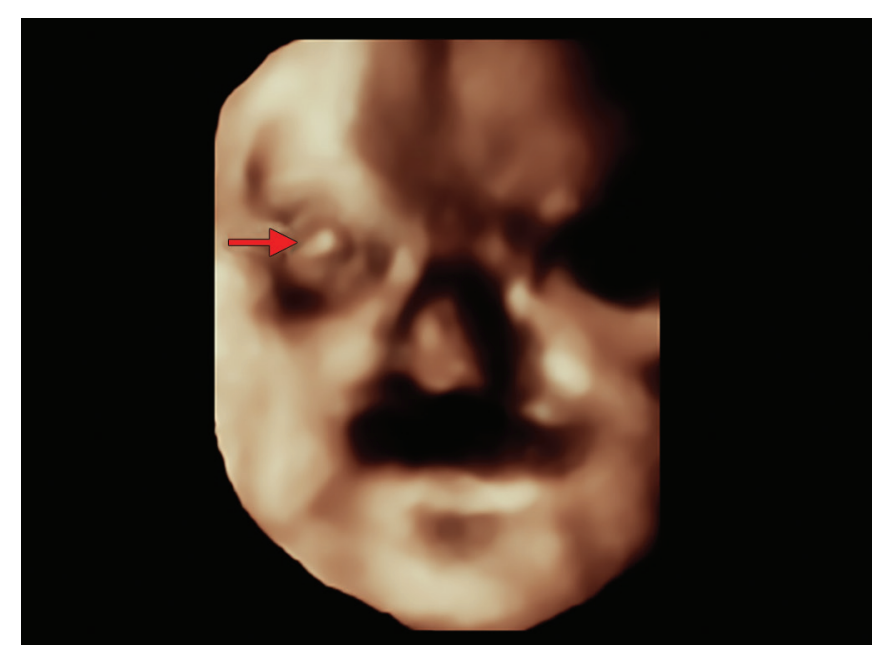

Fig. 7: Cataract (hyperechoic disk) in the right lens $(\rightarrow)$. Surface rendered image. 33 weeks' gestation 


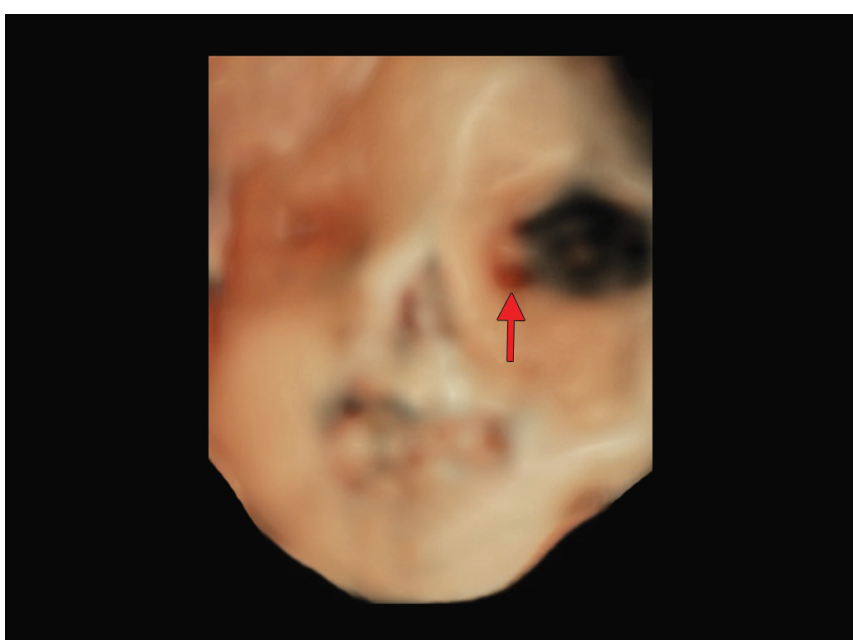

Fig. 8: Dacryocystocele in the inferomedial canthus left $(\rightarrow)$ Surface/transparent view of the face. 31 weeks' gestation

\section{Nasolacrimal Duct Cyst/Dacryocystocele}

The nasolacrimal duct cyst is a unilateral or bilateral benign cyst of the nasolacrimal duct. Embryogenesis is attributed to the failure of the valve of Hasnerat the distal end of the nasolacrimal duct. In dacryocystocele, there is an obstruction of the lacrimal drainage system both above (Rosenmuller valve) and below the sac (valve of Hasner). ${ }^{16,17}$

A lacrimal duct cyst/dacryocystocele appears sonographically as a cystic mass in the inferomedial canthus (Fig. 8). Dacryocystoceles are typically not identifiable until 30 weeks' gestation. ${ }^{18}$ In view of the fact that they may be a part of various syndromes, the investigator should carefully examine the fetus for other associated anomalies. ${ }^{19}$

\section{Cyclopia/Proboscis}

Cyclopia is a rare facial abnormality characterized by the failure of the embryonic prosencephalon to properly divide the orbits of one eye into two cavities. Instead of the nose, a proboscis is usually present,i.e., a trunk like appendage in the midline of the face originating above the eye level. Cyclopia and proboscis occur in association with holoprosencephaly. ${ }^{20,21}$

Ultrasound of the fetal face reveals a single orbit that is best demonstrated in the coronal or axial transparent view (Fig. 9A). The proboscis is best seen in a lateral surface view (Fig. 9B).

\section{NOSE ABNORMALITIES}

\section{Flat Nose (lat Profile)}

A flat profile is a known marker for a chromosomal abnormality (trisomy 21) in the second trimester. ${ }^{22-25}$

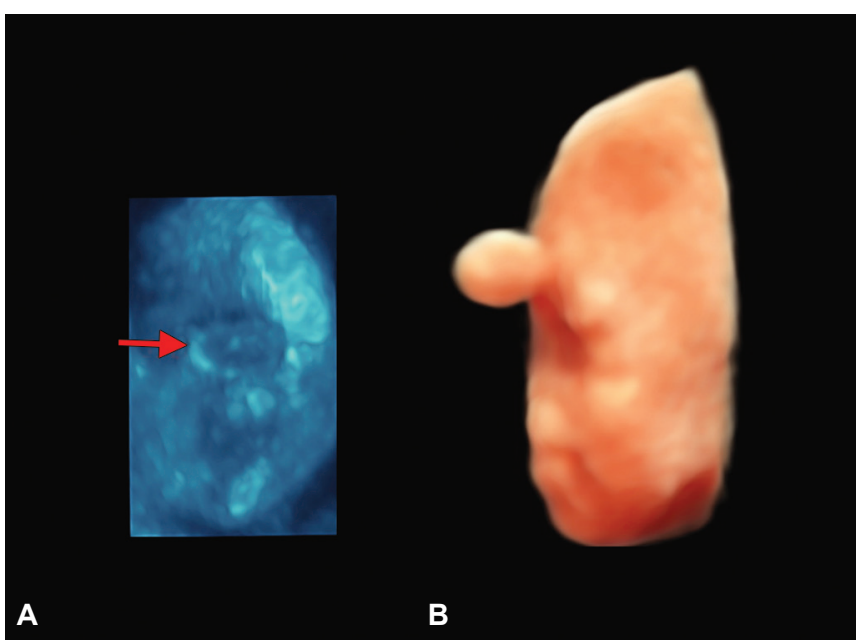

Figs 9A and B: Cylcopia with proboscis (24 weeks' gestation). (A)Transparent view of the face, showing one central orbit $(\rightarrow)$; (B) Lateral surface view of cyclopia with proboscis (HDlive)

One of the main advantages of 3D ultrasound technologyis the ability to provide the operator with a true median plane of the face, using the multiplanar mode. ${ }^{1}$ After identification of the precise profile in the multiplanar mode, several fetal measurements can be performed to confirm a flat profile..$^{24,26}$ A frontal fetal facial angle of $>145^{\circ}$ identified in the second trimester should raise suspicion for trisomy $21 .{ }^{24}$

A flat face can also be demonstrated with the surface mode from a lateral view (Fig. 10).

Every flat profile requires a targeted ultrasound examination with a diligent search for additional anomalies, and fetal karyotyping should be performed.

\section{Absent Nasal Bone}

Missing ossification of the two bilateral nasal bones is a further marker for trisomy $21.27,28$

3D ultrasound allows the identification of an absent nasal bone in both the multiplanar and the transparent mode (Fig. 11).

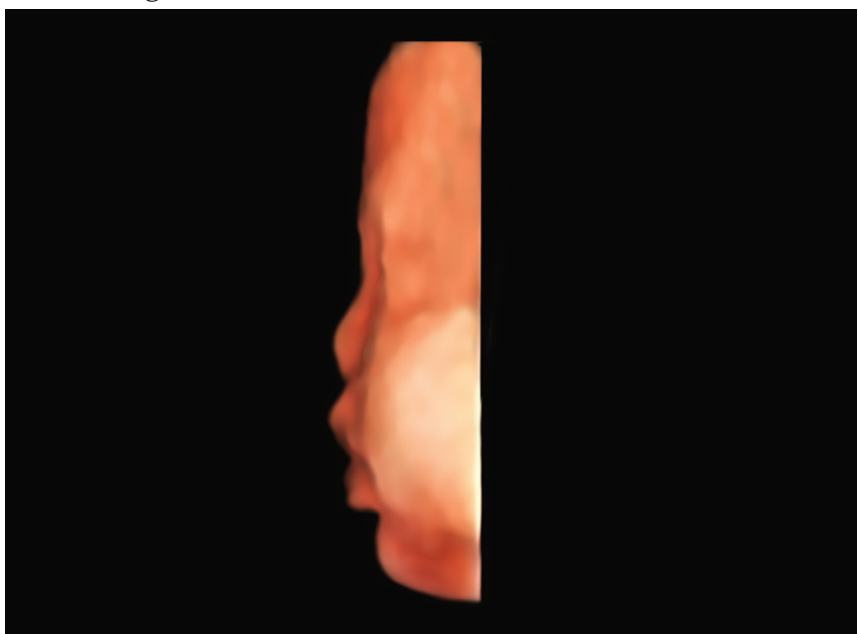

Fig. 10: Surface view of a fetus with trisomy 21, showing a flat profile (34 weeks' gestation) 


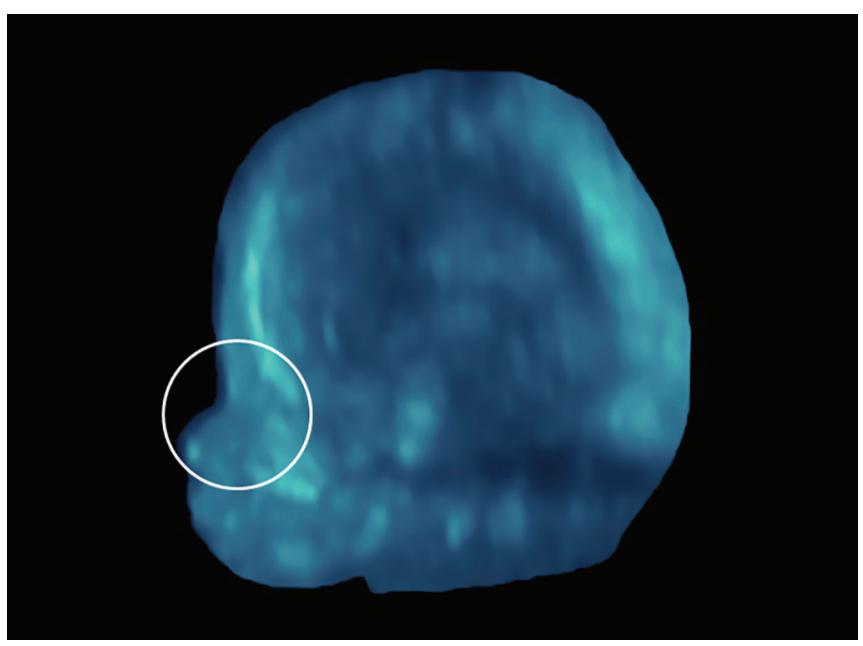

Fig. 11: Absent nasal bone in trisomy 21(O). Transparent side view (16 weeks' gestation)

\section{ABNORMALITIES OF THE MOUTH}

\section{Cleft lip/Cleft Palate}

Orofacial clefts are one of the most common congenital anomalies. The group of orofacial anomalies is heterogeneous. It comprises "typical" orofacial clefts [cleft lip (CL), cleft lip and cleft palate (CLP) and cleft palate only (CP)], as well as "atypical" clefts (median, transversal, oblique and other Tessier facial clefts). ${ }^{29}$

Both typical and atypical clefts can occur as an isolated anomaly, as part of a sequence of the primary defect, or as multiple congenital anomalies. ${ }^{29}$ More than 300 syndromes are associated with facial clefting. The most common chromosomal aberrations with orofacial clefts are trisomy 13, trisomy 18 and trisomy $21 . .^{29,30}$ Cleft lip and cleft palate can be unilateral, bilateral or median.

The ultrasound demonstration of different cleft lips is most successful in the surface mode (Fig 12). ${ }^{31}$ The detection of cleft palate is more difficult, particularly in the presence of an isolated cleft palate. Several 3D techniques have been described for the detection of cleft palate. ${ }^{1,32-35}$ The defect can be demonstrated in different modes: the multiplanar mode, tomographic mode, surface mode, and Omniview/VCR mode. ${ }^{35}$ The defect is most readily demonstrated when the fetus is yawning and the oral cavity is filled with amniotic fluid (Fig. 13).

Fetal karyotyping is recommended with a view to the risk for a chromosomal abnormality.

\section{Epignathus}

Epignathus is a rare type of teratoma arising in the oral cavity. In most cases, it is a benign tumor. However, it is associated with high mortality and morbidity rates because of severe airway obstruction and other

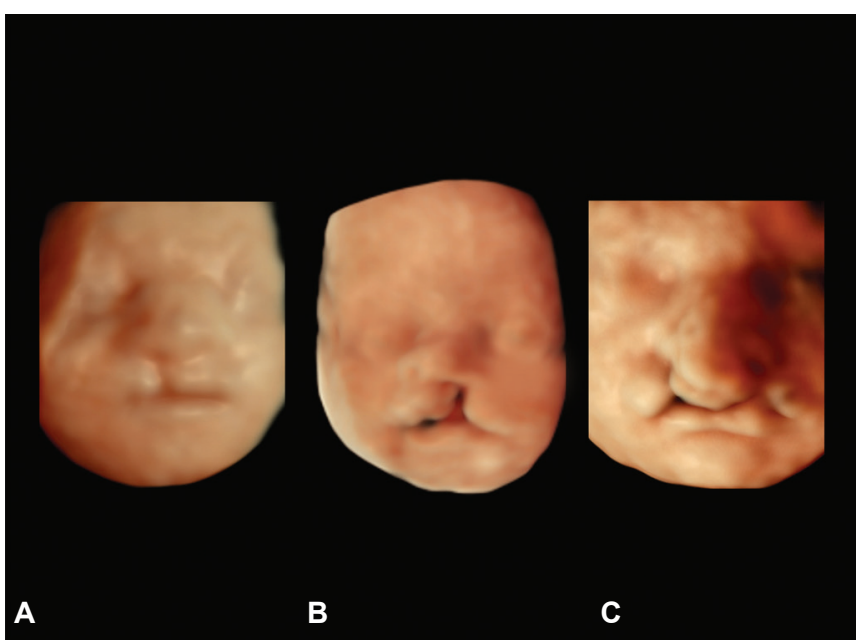

Figs 12A to C: Surface views (HDlive) of different cleft lip. (A) cleft lip right (30 weeks' gestation); (B) Cleft lip left (29 weeks' gestation); (C) Bilateral cleft lip (25 weeks' gestation)

malformations. ${ }^{36}$ Rare malignant cases have also been described in the literature. ${ }^{37}$

The 3D surface mode shows a solid tumor in front of the fetal mouth (Fig. 14).

\section{Macroglossia}

Macroglossia is a disorder characterized by an abnormal enlargement of the tongue. It may occur as an isolated and sporadic trait, as a familial trait, or in association with Beckwith-Wiedemann syndrome ${ }^{38}$ or Down syndrome. ${ }^{39}$

Ultrasound demonstration of macroglossia is best achieved in the surface mode and demonstrates an enlarged tongue in the open mouth (Fig. 15).

\section{Chin Anomaly}

\section{Micrognathia/Retrognathia}

Both micrognathia and retrognathia involve abnormal, arrested development of the mandible. Micrognathia

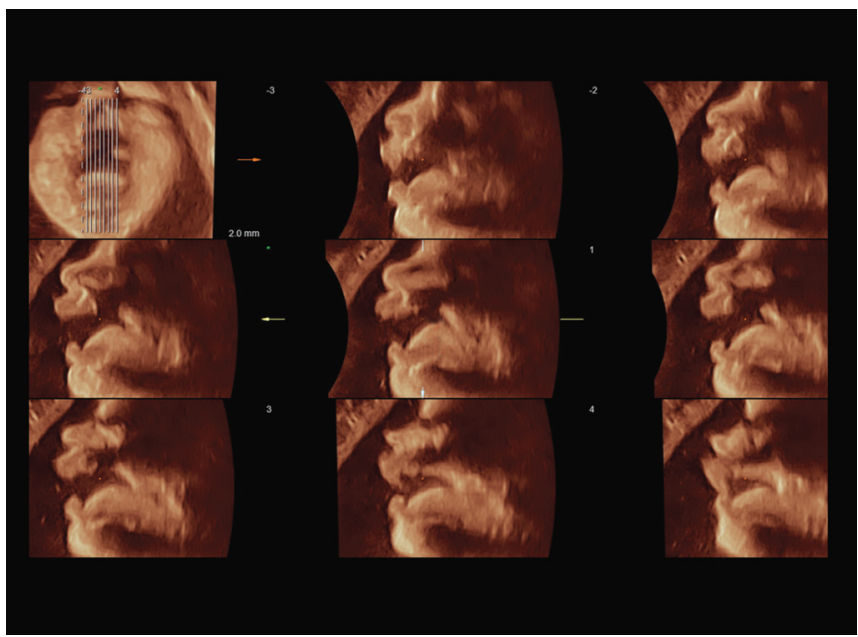

Fig. 13:Tomographic demonstration of a yawning fetus with cleft palate (34 weeks' gestation). The parallel sagittal planes of the face reveal a central defect of the palate $(\rightarrow)$ 


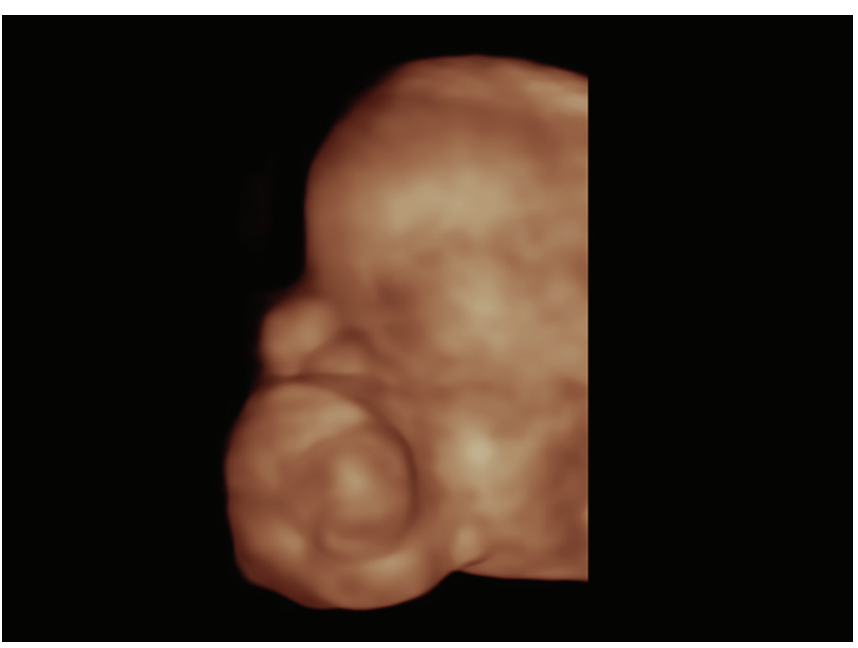

Fig. 14: Surface view of an epignathus arising as a solid mass from the oral cavity (22 weeks' gestation)

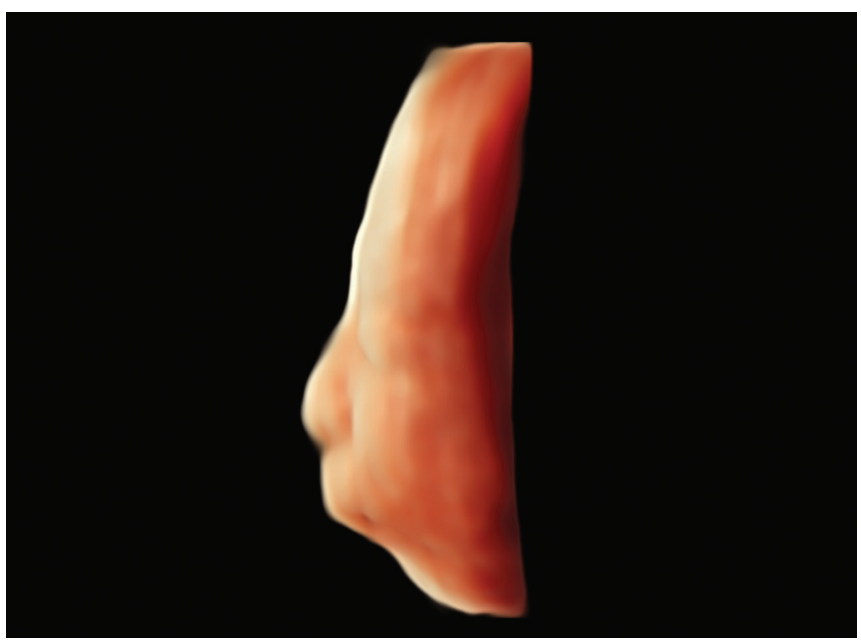

Fig. 16: Micrognathia at 24 weeks' gestation. The lateral surface representation shows small mandible

refers to the size of the mandible whereas retrognathia refers to its position in relation to the maxilla (Paladini). ${ }^{40}$

Micrognathia is frequently associated with a number of different syndromes, skeletal and neuromuscular diseases, as well as with chromosome anomalies (primarily trisomy 18). ${ }^{39-41}$

The sonographic diagnosis can be made on a subjective or objective basis. The subjective diagnosis is carried out by evaluating the midsagittal view of the facial profile and by assessing the geometric relationship between the mandible and the rest of the profile (Fig. 16). For an objective diagnosis, both the inferior facial angle (IFA) ${ }^{42}$ and the jaw index ${ }^{43}$ are used.

When micro-/retrognathia is detected, a detailed search for additional fetal abnormalities and fetal karyotyping is required.

\section{CONCLUSION}

3D ultrasonography allows a comprehensive evaluation of the fetal face with different display modes. In contrast to 2D ultrasound, 3D ultrasound enables a detailed

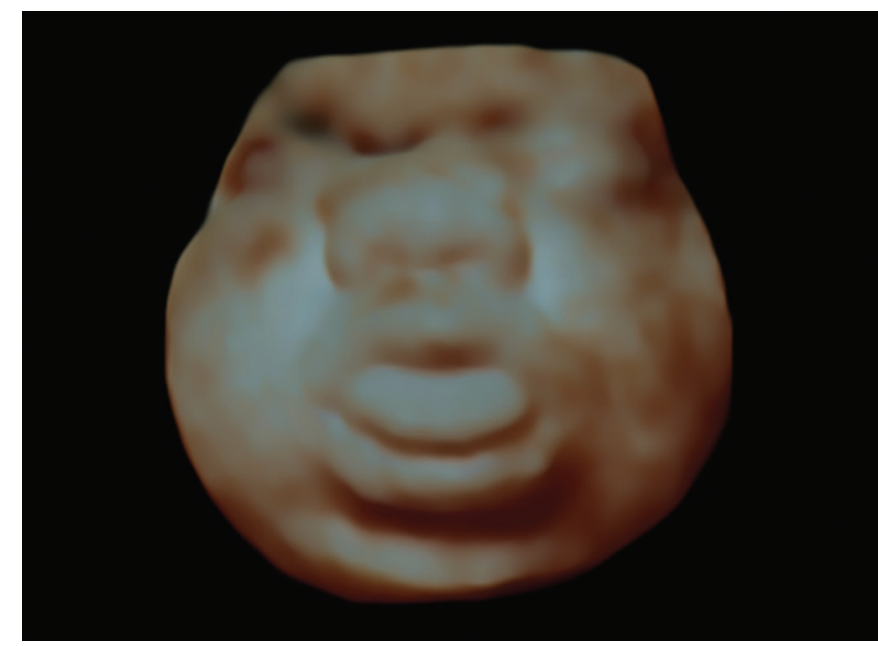

Fig. 15:Macroglossia in a fetus with trisomy 21 (27 weeks' gestation). The surface rendered image shows permanently open mouth with protruding enlarged tongue

demonstration of the soft tissue of the fetal face and thus contributes to a better understanding of the malformation by both the physician and the future parents. ${ }^{31}$

\section{REFERENCES}

1. Merz E, Abramovicz J, Baba K, et al. 3D imaging of the fetal face - recommendations from the International 3D Focus Group. Ultraschall Med. 2012;33:175-182.

2. Chatzipapas IK, Whitlow BJ, Economides DL. The `Mickey Mouse` sign and diagnosis of anencephaly in early pregnancy. Ultrasound Obstet Gynecol. 1999;13:196-199.

3. Becker R, Mende B, Stiemer B, et al. Sonographic markers of exencephaly at $9+3$ weeks of gestation. Ultrasound Obstet Gynecol 2000; 16(6):582-584.

4. Sepulveda W, Sebire NJ, Fung TY, et al. Crown chin length in normal and anencephalic fetuses at 10-14 weeks' gestation. Am J Obstet Gynecol. 1997; 176: 852-855.

5. Chaoui R, Levaillant JM, Benoit B, et al. Three-dimensional sonographic description of abnormal metopic suture in second- and third-trimester fetuses. Ultrasound Obstet Gynecol 2005;26:761-764

6. Donnenfeld AE, Hughes H, Weiner S. Prenatal diagnosis and perinatal management of frontoethmoidal meningoencephalocele. Am J Perinat 1988;5:51-53.

7. Weichert J, Hoellen F, Krapp M, et al. Fetal cephaloceles: prenatal diagnosis and course of pregnancy in 65 consecutive cases. Arch Gynecol Obstet. 2017;296:455-463.

8. Merz E, Wellek S, Püttmann S, et al. Orbital diameter, interorbital and biocular diameters - a growth model for fetal orbital parameters. Ultraschall in Med. 1995;16:12-17

9. Merz E (ed.). Ultrasound in Obstetrics and Gynecology. Vol. 1: Obstetrics. Thieme, Stuttgart - New York, 2005

10. Francois J. Genetics of cataract. Ophthalmologica 1982;184;6171

11. Francis PJ, Bery V, Bhattacharya SS, et al. The genetics of childhood cataract. J Med Genet. 2000;37,481-418.

12. Lambert S, Drack A. Infantile cataracts. Surv Ophthalmol 1996;40:427-45815.

13. Rahi JS, Dezateux C. Congenital and infantile cataract in the United Kingdom: underlying or associated factors. Invest Ophthalmol Vis Sci 2000;41:2108-2114 
14. Brasseur-Daudruy M, Vivier PH, Ickowicz V, et al. WalkerWarburg syndrome diagnosed by findings of typical ocular abnormalities on prenatal ultrasound. Pediatr Radiol 2012;42:488-490.

15. Drought A, Wimalasundera R, Holder S. Ultrasound diagnosis of bilateral cataracts in a fetus with possible cerebroocular congenital muscular dystrophy during the routine second trimester anomaly scan. Ultrasound 2015;23:181-185.

16. Cavazza S, Laffi GL, Lodi L, et al. Congenital dacrocystocele: diagnosis and treatment. Acta Otorhinolaryngol Italica 2008;28:298-301.

17. Barham HP, Wudel JM, Enzenauer RW, et al. Congenital nasolacrimal duct cyst/dacryocystocele: An argument for a genetic basis.Allergy Rhinol (Providence). 2012;3(1):e46-49.

18. Sherer D, Eisenberg C, Hammerman R, et al. Prenatal sonographic diagnosis of dacryocystocele: a case and rview of the literature. Amer J Perinatol 1997;14(8):479-481.

19. Sharon R, Raz J, Aviram R, et al. Prenatal diagnosis of dacryocystocele: a possible marker for syndromes. Ultrasound Obstet Gynecol 1999;14:71-73.

20. Olejek A, Bodzek P, Skutil M, et al. Cyclopia - literature review and a case report. Ginekol Pol. 2011;82:221-225.

21. Mălutan AM, Dudea M, Ciortea R, et al. Cyclopia and proboscis - the extreme end of holoprosencephaly. Rom J Morphol Embryol 2017,58:1555-1559

22. Sonek J, Borenstein M, Downing C, et al. Frontomaxillary facial angles in screening for trisomy 21 at 14-23 weeks' gestation. Am J Obstet Gynecol 2007; 197: 160.e1-5.

23. Vos FI, de Jong-Pleij EA, Bakker M, et al. Fetal facial profile markers of Down syndrome in the second and third trimester sof pregnancy. Ultrasound Obstet Gynecol. 2015;46:168-173.

24. Merz E, Pashaj S. The frontal fetal facial (FFF) angle in the second trimester measured by 3D ultrasound in normal fetuses and fetuses with trisomy 21. Ultrasound Obstet Gynecol 2015;46 (Suppl. 1):88.

25. Vos FI, Bakker M, de Jong-Pleij EA, et al. Is 3D technique superior to 2D in Down syndrome screening? Evaluation of six second and third trimester fetal profile markers. Prenat Diagn. 2015;35:207-213.

26. Vos FI, De Jong-Pleij EA, Ribbert LS, et al. Threedimensional ultrasound imaging and measurement of nasal bone length, prenasal thickness and frontomaxillary facial angle in normal second- and third-trimester fetuses. Ultrasound Obstet Gynecol. 2012;39:636-641.

27. Agathokleous M, Chaveeva P, Poon LC, et al. Meta-analysis of second-trimester markers for trisomy 21. Ultrasound Obstet Gynecol. 2013 Mar;41(3):247-261.

28. Du Y, Ren Y, Yan Y, et al. Absent fetal nasal bone in the second trimester and risk of abnormal karyotype in a prescreened population of Chinese women. Acta Obstet Gynecol Scand. 2018;97:180-186.

29. Tolarová MM, Cervenka J. Classification and birth prevalence of orofacial clefts. Am J Med Genet 1998;75:126-137.

30. Doray B, Badila-Timbolschi D, Schaefer E, et al. Epidemiology of orofacial clefts (1995-2006) in France (Congenital Malformations of Alsace Registry). Arch Pediatr. 2012;19: 1021-1029.

31. Merz E, Pashaj S. Prenatal detection of orofacial clefts. Ultraschall in Med 2016;37:137-139.

32. Campbell S, Lees C, Moscoso G, et al. Ultrasound antenatal diagnosis of cleft palate by a new technique: the 3D "reverse face" view. Ultrasound Obstet Gynecol. 2005;25:12-18.

33. Platt LD, Devore GR, Pretorius DH. Improving cleft palate/cleft lip antenatal diagnosis by 3-dimensional sonography: the "flipped face" view. J Ultrasound Med. 2006;25:1423-1430.

34. Pilu G, Segata M. A novel technique for visualization of the normal and cleft secondary palate: angled insonation and three-dimensional ultrasound. Ultrasound ObstetGynecol 2007;29:166-169.

35. Merz E, Pashaj S. Advantages of 3D ultrasound in the assessment of fetal abnormalities. J Perinat Med 2017;45:643-650.

36. Moon NR, Min JY, Kim YH, et al. Prenatal diagnosis of epignathus with multiple malformations in one fetus of a twin pregnancy using three-dimensional ultrasonography and magnetic resonance imaging. Obstet Gynecol Sci. 2015;58:65-68.

37. Too SC, Sarji SA, Yik YI, et al. Malignant epignathus teratoma. Biomed Imaging Interv J 2008;4:e18

38. Reish O, Lerer I, Amiel A, et al. Wiedemann-Beckwith syndrome: further prenatal characterization of the condition. Am J Med Genet. 2002;107:209-213.

39. Nicolaides KH, Salvesen DR, Snijders RJM, Gosden CM. Fetal facial defects: associated malformations and chromosomal abnormalities. Fetal Diagn. Ther. 1993;8:1-9

40. Paladini D. Fetal micrognathia: almost an ominous finding. Ultrasound Obstet Gynecol 2010;35:377-384

41. Luedders DW, Bohlmann MK, Germer U, et al. Fetal micrognathia: objective assessment and associated anomalies on prenatal sonogram. Prenat Diagn. 2011;31:146-151.

42. Rotten D, Levaillant JM, Martinez H, et al. The fetal mandible: a 2D and 3D sonographic approach to the diagnosis of retrognathia and micrognathia. Ultrasound Obstet Gynecol. 2002;19:122-30.

43. Paladini D, Morra T, Teodoro A, et al. Objective diagnosis of micrognathia in the fetus: the Jaw Index. Obstet Gynecol 1999;93:382-386. 